\title{
IMPRENSA ESPECIALIZADA EM EDUCAÇÃO: EM DESTAQUE O PERIÓDICO A INSTRUCÇÃO PUBLICA (1872-1875)
}

\author{
Sara Talitiane Viana Machado Leandro de Lima ${ }^{1}$ \\ Maria Cristina Machado ${ }^{2}$ \\ Mario Borges Netto ${ }^{3}$
}

\section{Resumo}

A pesquisa investiga o periódico especializado em educação A Instrucção Publica, criado por José Carlos Alambary Luz e publicado entre 1872 e 1875, no Rio de Janeiro. O periódico se apresentava com o objetivo de identificar os problemas da instrução pública brasileira e propor soluções para a sua organização. Entre os temas veiculados no periódico destacamse as publicações sobre a organização da instrução pública, com enfoque a formação de professores e os métodos de ensino. A imprensa especializada constitui importante fonte para a história da educação, por apresentar os debates travados pelos diversos grupos. No caso do periódico em estudo, constituiu importante espaço para divulgação de conteúdo educacional, em um período em que a imprensa se constituía como um dos principais veículos de divulgação das proposições dos homens que se envolviam na organização da sociedade, e, consequentemente, da instrução pública.

Palavras-chave: História da educação. Imprensa especializada em educação. A Instrucção Publica. Império.

\section{PRESS SPECIALIZING IN EDUCATION: THE CASE OF THE JOURNAL A INSTRUCÇ̃̃O PUBLICA (1872-1875)}

\begin{abstract}
The research investigates the journal specialized in education called A Instrucção Publica. The journal was created by José Carlos Alambary Luz and published between 1872 and 1875 in Rio de Janeiro, Brazil. The journal was presented for the purpose of identifying the problems of the Brazilian public education and proposing solutions for its organization. Among the themes published in the journal, it can be highlighted the publications about the organization of public education, focusing on teacher training and teaching methods. The specialized press is an important source for the history of education and has presented the debates waged by several groups. In the case of the journal aforementioned, it was an important space for the dissemination of educational content. This occurred in a period in which the press constituted as one of the main vehicles of dissemination of the propositions of the men involved in the organization of the society and the public instruction.
\end{abstract}

Keywords: History of education. Press specializing in education. The journal A Instrucção Publica. Empire times. 


\title{
PRENSA ESPECIALIZADA EN EDUCACIÓN: EN CUESTIÓN EL PERIÓDICO A INSTRUCÇ̃̃O PUBLICA (1872-1875)
}

\begin{abstract}
Resumen
El estudio investiga el periódico especializado en educación llamado A Instrucção Publica. El periódico fue creado por José Carlos Alambary Luz. Fue publicado entre 1872 y 1875 en Rio de Janeiro, Brasil. El periódico fue presentado con el objetivo de identificar los problemas de la educación pública brasileña y proponer soluciones para su organización. Entre los temas publicados en la revista se encuentran las publicaciones sobre la organización de la educación pública, centrándose en la formación docente y en los métodos de enseñanza. La prensa especializada es una fuente importante para la historia de la educación porque presenta los debates de los distintos grupos. En el caso de este periódico, se trataba de un espacio importante para la divulgación de contenidos educativos. Esto ocurrió en un período en que la prensa se constituyó como uno de los principales vehículos de difusión de las proposiciones de los hombres involucrados en la organización de la sociedad, y de la instrucción pública.
\end{abstract}

Palabras-clave: Historia de la educación. Prensa especializada en educación. El periódico A Instrucção Publica. Imperio.

\section{INTRODUÇÃO}

O objetivo deste texto é investigar o periódico especializado em educação $\mathbf{A}$ Instrucção Publica ${ }^{4}$, publicado na capital imperial, entre os anos de 1872 e 1875 . Criado por José Carlos Alambary Luz (1832-1915), naquele momento era professor da Escola Normal da Província do Rio de Janeiro, o periódico tinha como principal objetivo a promoção da discussão sobre a organização da escola pública primária.

Utilizar a imprensa especializada em educação como objeto e fonte para a escrita da história da educação, justifica-se pelo papel que desempenha frente aos debates que circulam na sociedade. No caso do período imperial, a imprensa desempenhou importante papel na veiculação de diferentes posicionamentos para a organização do país. A imprensa como objeto de reflexão do historiador permite a apreensão das rupturas e continuidades promovidas na sociedade e a identificação das interpretações que dialogam em discordância no espaço social. (MACHADO; RODRIGUES, 2017).

As pesquisas históricas tornam-se possíveis à medida que os documentos são preservados. No caso da imprensa, a Hemeroteca Digital da Biblioteca Nacional mantém amplo acervo sobre os impressos produzidos no Brasil. O periódico em estudo está disponível digitalizado na íntegra e em bom estado de conservação. 
Os estudos com a imprensa devem considerar o contexto de produção, uma vez que é um "[...] produto histórico-social, determinado por fatores sociais, políticos e econômicos, inter-relacionados.” (MACHADO; CARVALHO, 2016, p. 13). É essencial a confrontação com as diversas possibilidades de fontes produzidas no período de circulação do impresso. A pesquisa em questão utilizou, como fonte, documentos produzidos no século XIX, tais como leis, decretos e relatórios, as edições do periódico e a historiografia educacional, constituindo-se como uma pesquisa de caráter bibliográfica e documental.

Na segunda metade do século XIX, diversos segmentos da sociedade pretendiam adequar seu discurso ao que era tido como novo e moderno. Buscavam consolidar seus interesses em um cenário que estabelecia como necessidade adequar o Brasil aos moldes de nação civilizada exportada pelos europeus. Ao mesmo tempo, a urgência da transição do trabalho escravo para o trabalho assalariado e a dificuldade em preparar o trabalhador para atuar na agricultura e na incipiente indústria.

Nesse cenário, a ação educativa se deu por meios específicos, na qual a imprensa, especialmente a periódica, teve papel fundamental para a reorganização da sociedade brasileira. Enquanto um dos principais meios para a disseminação de ideias, os periódicos debatiam sobre as questões sociais, políticas, econômicas e educacionais, buscando formar o leitor dentro do ideal de sociedade que defendia.

A década de 1870 vivenciou a intensificação dos debates sobre a instituição da instrução pública para as classes populares. Esse movimento apareceu em projetos educacionais propostos na esfera legislativa, na criação de jornais e revistas dedicados a educação, na tradução e produção de compêndios escolares, na organização de conferências pedagógicas, entre outros.

A formação de professores primários foi uma das preocupações do período destacado. De acordo com Villela (2002), entre os anos de 1860 e 1880, a formação de professores se transformou do modelo artesanal para o modelo profissional. O aprendizado guiado pela observação e pela prática da profissão passou para a formação institucionalizada, fundamentada no conhecimento teórico e prático.

No período imperial, as instituições de formação docente eram escassas. Nesse sentido, em consonância ao debate em vigência nos anos de 1870, o periódico A Instrucção Publica se propôs a identificar os problemas da instrução pública brasileira e apresentar propostas para sua organização, entre eles, modelos de ensino para aperfeiçoamento da prática docente. Em seus textos, o periódico divulgou conteúdo de caráter teórico e prático e objetivava contribuir com a profissionalização do magistério atuante na província do Rio de Janeiro.

Na próxima seção serão apresentados A Instrucção Publica, o editor Alambary Luz e algumas das proposições divulgadas pelo periódico sobre a instrução pública. 


\section{O PERIÓDICO A INSTRUCÇÃO PUBLICA: IMPRESSO ESPECIALIZADO EM EDUCAÇÃO PARA A ORGANIZAÇÃO DO ENSINO PÚBLICO}

De acordo com Almeida (1989) ${ }^{5}$, o periódico criado por Alambary Luz foi o primeiro do gênero. Para ele, Alambary Luz fazia parte do grupo de estudiosos que promoveram progressos na educação nacional. Descreveu-o como o "[...] fundador, no Brasil, da imprensa didática. A ele deve-se a criação de uma excelente publicação periódica, a Instrucção Publica que contém úteis ensinamentos para os institutores.” (ALMEIDA, 1989, p. 173). Já Bastos (2002), em levantamento sobre os periódicos educacionais produzidos no Brasil, identificou a existência de periódicos que se dedicavam a temas relativos à educação e ao ensino, tais como o Jornal de Instrução e Recreio, Maranhão, 1845-1846; a Revista Universal Brazileira, Rio de Janeiro, 1848; a Gazeta da Instrução Pública, Niterói, 1851-1852; a Revista Popular, Rio de Janeiro, 1859-1862, dentre outros. O que se observa, pela descrição dos títulos e subtítulos dos periódicos fundados anteriores A Instrucção Publica e apresentados por Bastos (2002), é a veiculação diversificada de conteúdos, entre eles, o ensino e a instrução pública.

Alambary Luz, principal editor do periódico A Instrucção Publica, era bacharel em ciências sociais e jurídicas, pela Faculdade de Direito de São Paulo. Para além da função de diretor do periódico, exerceu a função de inspetor do Município Neutro, cargo não remunerado, que lhe atribuía o papel de fiscalizar as escolas públicas e particulares da Freguesia de Paquetá. (SCHUELER, 2005). Destacou-se como diretor da Escola Normal da Província do Rio de Janeiro, entre 1868 e 1876, período no qual a escola experimentou muitas mudanças curriculares e programáticas, tidas como inovadoras e modernas no período, dentre elas, a negação dos castigos corporais e a introdução do método intuitivo na formação dos professores. (VILLELA, 2007).

A posição político-partidária de Alambary Luz não era explícita nas publicações do periódico, uma vez que os textos enfatizavam as questões pedagógicas. Pelo seu posicionamento quanto à organização da instrução pública é possível colocá-lo no grupo dos que defendiam que a educação seria o caminho seguro para alcançar o progresso do país. De acordo com Villela (2002), as ações de Alambary Luz sintonizavam com o grupo liberal. A própria indicação ao cargo de diretor da Escola Normal da Província do Rio de Janeiro, pelo liberal Américo Brasiliense, após destituição do diretor Felippe José Alberto, refletia a aproximação de Alambary Luz ao grupo liberal.

A atuação de Alambary Luz foi destacada com frequência na imprensa diária. Em 1862, o Diário do Rio de Janeiro noticiou a eleição de Alambary Luz para deputado pelo $3^{\circ}$ distrito eleitoral da província do Rio de Janeiro. Em 1871, foi publicada sua nomeação como membro do conselho da instrução pública. Se em 1878, o jornal O Cruzeiro informaria a nomeação de Alambary Luz para o cargo de delegado do inspetor geral da 
instrução primária e secundária, na freguesia de Paquetá, no ano de 1892, a Revista Pedagogica lamentaria seu desligamento.

[...] o Sr. Dr. J. C. Alambary Luz deixou o cargo de inspetor escolar. Nossos pezames à instrucção publica e principalmente ao Sr. Dr. Inspector Geral que perdeu um dos mais illustrados e zelosos collaboradores. O Dr. Alambary Luz pertence ao numero, não muito avultado, d'aquelles que entre nós ainda esperam a regeneração da Pátria pela educação popular. (REVISTA PEDAGÓGICA, 1892, p. 50).

Ao fundar A Instrucção Publica na década de 1870, Alambary Luz pretendia criar um espaço onde pudesse divulgar suas proposições. Com a contribuição de alguns colaboradores, o periódico tinha por objetivo discutir acerca da instrução pública, sobretudo, no que dizia respeito à organização do ensino primário. $\mathrm{O}$ corpo de colaboradores do periódico era formado por advogados, médicos, professores primários, farmacêuticos, bacharel em letras, secretário da instrução pública, diretor de escola pública e particular, político, quase todos residentes no Município Neutro ou na Província do Rio de Janeiro.

Entre os colaboradores, o periódico destacou os conselheiros Pedro Autran da Matta e Albuquerque Junior, José Liberato Barroso e Benevenuto Augusto de Magalhães Taques; os professores Antonio Estevão da Costa e Cunha, Augusto Candido Xavier Cony, Abílio César Borges / barão de Macahubas, Antonio Severino da Costa, Carlos Brazil, Francisco Alves da Silva Castilho e Antonio Joaquim Teixeira Azevedo.

A fundação do periódico foi bem recebida pelo Diário do Rio de Janeiro, um dos mais proeminentes jornais da província: “[...] é incontestavel que esta publicação vem preencher uma lacuna de ha muito sentida em nossa sociedade por todos os sinceros amigos do progresso e da civilização.” (DIÁRIO DO RIO DE JANEIRO, 1872, p. 1). Defendeu que o estímulo do poder público e particular não deveria faltar ao periódico de Alambary Luz, pois este tinha como objeto a instrução pública, aquilo que precisava ser considerado por todos. O Jornal do Commercio também anunciou a criação do periódico.

O próprio periódico A Instrução Pública atribuiu à imprensa especializada em educação o papel de propulsora do progresso e desenvolvimento do ensino e defendeu a importância dos periódicos para o desenvolvimento da instrução.

JORNAES PEDAGOGICOS. Nos paizes em que a instrucção popular é uma verdade, consideram-se os jornaes que se dedicam exclusivamente à pedagogia e à causa da instrucção, como elementos dos mais poderosos e eficazes para o progresso e desenvolvimento do ensino, e as razões são obvias. Nos Estados Unidos ha 24 folhas especiaes da matéria; nos outros paizes publicam-se tambem diversas, mas não em numeros tão avultado em um só paiz. Temos noticiais das seguintes: Revista pedagogica (Lisboa); Journal general de l'instruction publique (Paris); L'institutore; La guida del maestro elementare italiano (Italia). Entre nós publicam-se a Revista mensal da instrucção, em Pernambuco; outra Revista, na Bahia; e na côrte, além da Instrucção Pública, o orgam do 
magisterio primario oficial. (A INSTRUCÇÃO PUBLICA, 1872f, p. 164, grifo nosso).

O professor Costa e Cunha, colaborador assíduo daquele, afirmou que se dedicar à imprensa pedagógica seria o mesmo que "[...] servir a causa do ensino publico, o que é o mesmo que servir ao progresso e engrandecimento da nação." (A INSTRUCÇÃO PUBLICA, 1872h, p. 242). Enquanto um veículo especializado em educação, percebe-se a intenção de se afirmar a importância dos periódicos de cunho pedagógico em contribuírem e exercerem papel relevante para o progresso do país.

O periódico circulou em dois momentos: entre os anos de 1872 e 1875, foram publicadas 164 edições, com tiragem semanal e variação de oito ou 12 páginas. Já entre 1887 e 1888 foram publicadas 19 edições, com tiragem quinzenal e variação de oito ou 12 páginas, totalizando 183 edições. Como já citado anteriormente, esse texto tratou sobre os editoriais publicados na primeira fase de circulação do periódico. Alambary Luz não ocupou o cargo de diretor do periódico apenas no ano de 1875, função desempenhada por José Joaquim do Carmo e José Rodrigues de Azevedo Pinheiro.

Não há informações no periódico sobre a quantidade de tiragem de cada edição. Entretanto a edição de n. 27 de 1872, em texto assinado por Alambary Luz, comunicou aos leitores que o Ministério dos Negócios do Império havia autorizado a aquisição de assinaturas para os professores públicos que atuavam no Município Neutro. O texto destacou que $\mathrm{o}$ ato de apoio das autoridades imperiais demonstrava muito mais apoio moral do que econômico, uma vez que havia apenas 65 professores, ou seja, 65 assinaturas.

S. Ex o Sr. Conselheiro Dr. João Alfredo Corrêa de Oliveira autorizou a inspectoria geral da instrucção primaria e secundaria do municipio da côrte a tomar tantas assignaturas da Instrucção Publica quantos são os professores primarios do municipio neutro para lhes ser remetido este hebdomadario por conta do respectivo ministério. (A INSTRUCÇÃO PUBLICA, 1872g, p. 229).

Na última publicação de 1874, datada no dia 27 de dezembro, o periódico comunicou que "[...] a Província do Rio de Janeiro, em virtude de seus apuros financeiros, não nos pagou as quinhentas e tantas assinaturas recebidas desde janeiro ultimo até hoje para suas camaras municipaes, escolas, bibliotecas.” (A INSTRUCÇÃO PUBLICA, 1874, p. 460). Com essa nota pode-se constatar que no ano de 1874, só para a província foram impressas 500 cópias. Para Alambary Luz, o ato de o periódico ser distribuído aos professores custeados pelo governo demonstrava a preocupação deste para com o ensino público.

O periódico não apresentou uma disposição fixa das seções, mas trouxe regularidade em quase todas as edições de algumas seções. De modo geral, dividia-se em um texto principal, assinado por Alambary Luz, em algumas edições assinadas por outros colaboradores. Com raras exceções, o editorial não se apresentou como o primeiro da edição. Havia textos assinados por colaboradores fixos, algumas vezes textos sem assinatura e textos 


\title{
Revista HIISTEYIDIR On-line
}

Artigo

doi: $10.20396 /$ rho.v18i2.8652187

enviados por professores públicos. Alguns textos eram publicados em várias edições, geralmente os que reproduziam obras ou eram enviados por colaboradores.

Os assuntos variavam desde publicações sobre a instrução pública no geral, como o ensino de ginástica, castigos corporais, ensino obrigatório e livre, higiene, a temas mais específicos como lições para o ensino da aritmética e da língua materna, métodos de ensino, regras gramaticais, textos literários como os de J. Macé e Rosely de Lorgues. Textos sobre economia, fisiologia humana, poesias, charadas, traduções de documentos e obras educacionais, atas das sociedades literárias, das repartições públicas, legislação educacional e a seção fixa denominada Noticiário fizeram parte do periódico.

Ao traduzir e publicar obras de autores brasileiros e estrangeiros, o periódico pretendia diminuir o desconhecimento dos autores tidos como clássicos e essenciais.

\begin{abstract}
Entendemos por tanto fazer um serviço à mocidade estudiosa transcrevendo trechos importantes em prosa e verso que lhes devam ser familiares, mas que por se acharem esparsos em custosos livros não estejam ao alcance de todas as fortunas. Nem a isso nos limitaremos; a exemplo de publicações estrangeiras, análogas a esta nossa, forneceremos leitura para todas as condições, grave e substancial para os professores, facil e amena para os discipulos, escolhida e agradavel para todos. (A INSTRUCÇÃO PUBLICA, 1872a, p. 2).
\end{abstract}

Entre os autores que tiveram transcritos ou resenhados textos no periódico, está o brasileiro Abílio César Borges, conhecido por sua atuação no ensino particular, ao fundar, no Rio de Janeiro e em Minas Gerais, o Colégio Abílio. Como literatura estrangeira, apareceram os textos de Johann Pestalozzi, precursor da pedagogia moderna, utilizados na fundamentação teórica do método intuitivo, e de Celestin Hippeau, professor francês, conhecido pelos seus relatórios sobre a instrução pública.

O contexto de produção do periódico se insere em um momento de disputas sobre o encaminhamento político, econômico e social do país. O Brasil do século XIX vivenciou diferentes conjunturas econômicas, políticas, culturais e sociais, passando de colônia exportadora, dependente da metrópole portuguesa, à sede do reino português, em 1808, declarando a independência em 1822 e constituindo império até 1889, quando foi proclamada a república. Entre o início da década de 1870 e o fim da década de 1880 o Brasil vivenciou mudanças significativas. Em 1873 foi criado o Partido Republicano, influenciando na queda do império e na Proclamação da República em 1889. (MACHADO, 2002).

A década de 1870, momento bastante significativo na história do Brasil, foi marcada pelo início das crises que resultariam no fim do Império, na abolição da escravidão e na Proclamação da República, modificando significativamente a organização da sociedade em seus aspectos sociais, políticos e econômicos. Nessa década diversas propostas de reforma do ensino público foram elaboradas, destacando-se as de Paulino José Soares de Souza (1870), Antônio Cândido Cunha Leitão (1873), João Alfredo Corrêa de Oliveira (1874) e o decreto de Leôncio de Carvalho (1879) ${ }^{6}$. 
Ao estudar a década de 1870, Calvi (2003) enfatiza a quantidade de propostas para a instrução pública nesse período, uma vez que, anterior ao projeto de Paulino Souza de 1870, foi implementada a reforma Couto Ferraz de 1854, ou seja, por 16 anos não foi apresentada nenhuma proposta de reforma para a instrução pública na capital do Império. O periódico $\mathbf{A}$ Instrucção Publica foi produzido em meio a esse debate, e, como o próprio nome já demonstra, buscava apresentar propostas para a educação pública.

Na primeira edição do periódico, publicado em 13 de abril de 1872, o texto intitulado Apresentação, e assinado por Alambary Luz, expunha eloquente discurso sobre a instrução pública e sobre a finalidade da criação do periódico. Ao tratar acerca da necessidade de um espaço para debates a respeito da oferta da educação popular, Alambary Luz apresenta a criação do periódico como um espaço para discussão sobre a instrução pública, colocandoa como a primeira necessidade dos povos, pois seria ela quem direcionaria o espírito dos povos. O mesmo comprometeu-se a tratar no periódico dos assuntos complexos da instrução pública e indicar os caminhos para melhorá-la.

No movimento geral das idéas, quotidianamente agitadas pelo jornalismo brazileiro, uma sobresahe que attingio, ha muito, por sua elevada importancia e incontestavel urgencia, as proporções de aspiração nacional.

Essa idéa que tomamos a peito desenvolver, quanto nossas forças o permitam, foi ainda a que suggerio o título desta folha hebdomadaria.

A instrucção publica se tem tornado a primeira necessidade dos povos, porque é delles o pharol e alimentação espiritual.

[...]

E' para estudar as questões complexas da instrucção publica e apontar os meios de melhoral-a que se funda esta folha.

Conservando a discussão na altura que convem a questões meramente litterarias, mas de reconhecido, de immediato interesse publico, descobriremos todos os vícios da educação social e abriremos espaço para a enunciação de todas as opiniões sem a menor alusão a personalidades.

$[\ldots]$

Nossa maior attenção entretanto se volverá para a instrucção primaria, a mais negligenciada de todas, e a base indispensavel, não diremos dos estudos clássicos, mas da grandeza futura desta terra de Santa Cruz. (A INSTRUCÇÃO PUBLICA, 1872a, p. 1-2).

Por meio do texto se evidencia a inquietação em relação ao ensino público que era oferecido no período. A necessidade de uma reformulação na educação em prol da modernização do país foi um dos motivos da criação do periódico. As inquietações reclamavam remuneração adequada, docentes capacitados, expansão do currículo escolar, entre outras. A instrução pública como um projeto de sociedade moderna necessitava de atenção, a fim de alcançar, na perspectiva do periódico, um ensino que propiciasse ao povo o crescimento material, moral e intelectual.

A tese que justifica a criação do periódico fundamenta-se na crença de que pela instrução modernizar-se-ia o Brasil. Essa instrução deveria ser de qualidade e atingir seus fins de propulsora da civilidade. O periódico contribuiria, apontando os problemas e 
soluções, propondo-se a explorar os vícios da educação, fazendo menção de abrir espaço de publicação para as diversas opiniões sobre a instrução, sem se intimidar por nenhuma personalidade que viesse a se opor ao conteúdo veiculado no periódico. A existência do periódico nortearia em denunciar a precariedade da instrução brasileira e propor novos caminhos para alcançar um ensino público que atingisse aos seus fins, o progresso do país e a modernização da sociedade.

O periódico A Instrucção Publica se preocupou em propor modelos de organização da escola pública primária. Conscientes de que, para além de modernizar a escola pública brasileira, era necessário estruturá-la primeiro, as publicações apontaram soluções para diversos problemas. Embora muitos modelos educacionais do exterior tenham sido apresentados como exemplos para a organização da instrução, as propostas reconheciam as especificidades da realidade brasileira e propunham adequações para serem aplicadas nas escolas brasileiras, propondo modelos de ensino elaborados por brasileiros.

O periódico comprometeu-se, desde sua primeira publicação, a atuar na veiculação de propostas de melhoria para a instrução pública. Evidenciou o caráter de que, pela instrução, todos os problemas do país seriam resolvidos, tomando a educação como ponto central do projeto de modernização, empreendido por diversos setores da sociedade. Na primeira edição destacou que "O remedio para todos estes males apenas esboçados, mas sentidos em demasia por nós brasileiros, é um unico, simples e poderoso: a educação nacional por meio da instrucção popular." (A INSTRUCÇÃO PUBLICA, 1872a, p. 1-2).

A preocupação do periódico em debater sobre a organização da educação pública era por acreditar que esse seria o caminho mais rápido para transformar o Brasil em um país desenvolvido e moderno, tais quais os países europeus, frequentemente chamados para conferir legitimidade às propostas educacionais publicadas. A economia do país era movida pelas lavouras de café, pautada no sistema de produção escravocrata. A maior parte da população era pobre e analfabeta e não tinha acesso à leitura, o que dificultava a politização. (MACHADO, 2008). Dados retirados do Repertório Estatístico do Brasil (INSTITUTO BRASILEIRO DE GEOGRAFIA E ESTATÍSTICA, 1986) indicam que, no ano de 1872, havia 10 milhões de brasileiros, apenas 4.552 escolas, com o total de 139.321 matrículas. No Município Neutro havia 266 mil habitantes, com 174 escolas e 8.433 matrículas. O relatório estatístico apresentado pelo conselheiro José Bento da Cunha Figueiredo, em 1876, apontou que 1.563.078 dos habitantes livres sabiam ler e escrever contra 6.856.000 que não sabiam. Os analfabetos totalizam $80 \%$ da população livre e $99,9 \%$ dos escravos. (BRASIL, 1877).

No século XIX, o Brasil passou por transição na organização no modo de trabalho, na política e na economia. Foram mudanças necessárias para que o país pudesse se inserir no movimento universal, como a modificação do trabalho escravo para o livre assalariado. A segunda metade do século XIX se caracterizou por mudanças na ordem mundial do capital, 
propiciada pela crise de superprodução, vivenciada em diversos países. Em nível mundial, a expansão da indústria na Europa promoveu transformação nas forças produtivas, provocando a superprodução e o desemprego. (SCHELBAUER, 1997).

Ao pretender apropriar-se das relações de produção dos países europeus, o Brasil vivenciou transformações em níveis econômico, social, político e cultural que impactaram na organização da sociedade. Enquanto país do novo mundo, precisava adaptar-se ao movimento mundial e modernizar-se acompanhando as mudanças do modo de produção capitalista, sobretudo, modificar suas formas de trabalho, predominantemente escravocratas. Alterar a forma de trabalho implicava outras mudanças, entre elas a "[...] modernização da sociedade civil, como o fim da monarquia, a separação entre a Igreja e o Estado, a adoção do casamento civil, a secularização dos cemitérios, a reforma eleitoral, o incentivo à imigração e à industrialização." (MACHADO, 2006, p. 91).

Dessa forma, o processo de modernização do trabalho acarretou os debates sobre a educação popular, revelando que "[...] a luta dos homens para a produção de suas vidas" (SCHELBAUER, 1997, p. 20) confundia-se com os debates sobre a educação. Os debates sobre o destino do país incorporavam trabalho, educação e progresso como saída para a crise vivenciada na nação, alcançando os congressos agrícolas, projetos e decretos, intelectuais e a imprensa. As discussões em torno da instrução popular, na segunda metade do século XIX, se davam, especialmente, para a formação dos pobres livres, ingênuos e imigrantes. (SCHELBAUER, 1997).

A partir da década de 1870, a valorização das inovações pedagógicas para a instrução, sobretudo estrangeiras, acompanhou o movimento dos países da Europa e dos Estados Unidos. Nessa perspectiva, propostas metodológicas e curriculares, programas de ensino, materiais didáticos, entre outros, aportaram no Brasil e foram adaptados às necessidades e à realidade educacional brasileira. (VILLELA, 2002).

Ao buscarem atender à modernização da sociedade, os debates sobre a urgência da criação da escola pública se propagaram. Conhecido como o século no qual se institucionalizou a educação pública, o século XIX presenciou vários países que organizaram seus Sistemas Nacionais de Ensino. A escola pública, em nível primário, foi a que mais recebeu atenção no que se refere à educação popular. Com o intuito de organizar as classes trabalhadoras por intermédio da educação, a instrução popular vinculava-se ao discurso de universalização do ensino, propiciando a educação moral e a cidadania, além de promover os conhecimentos básicos essenciais aos processos de produção das organizações industriais. (KUHLMANN JUNIOR, 2006).

No periódico A Instrucção Publica, a educação pública apareceu como a responsável por formar o cidadão, promover o sentimento nacional e propiciar a modernização do país. A escola seria a instituição com a capacidade de regenerar a sociedade. A ideia de que, pela instrução, se alcançaria o progresso das nações ditas 


\section{Revista HIISTEYIDIR On-line}

civilizadas, uma constante nas publicações do periódico, era algo presente naquele período. Sobre isso, Villela (2007, p. 103) afirma que

[...] os dirigentes que assumem o poder nas várias províncias no período regencial, sintonizados com o pensamento iluminista que marcou fortemente as idéias pedagógicas da época, tanto na Europa quanto no novo continente, acreditavam de forma conveniente aos seus interesses que somente pela instrução se atingiria os estágios mais elevados da "civilização". Elegendo as nações europeias como o modelo mais aperfeiçoado, entendiam que a falta de instrução do nosso povo era a verdadeira causa da distância existente entre o Brasil e as nações civilizadas.

O discurso em prol da civilização do Brasil fundamentou os projetos políticos e medidas administrativas realizadas pelos dirigentes do Império. O termo que se transformou em "[...] uma espécie de panacéia para legitimar ações que se afirmavam como meio de superação para os males e problemas sociais" (GONDRA; SCHUELER, 2008, p. 69) foi tomado como justificativa para legitimar a necessidade de o Estado organizar a instrução ao povo.

Alambary Luz destacou a importância da instrução para a efetivação dos governos, uma vez que, pela instrução, poderiam difundir seus ideais.

[...] a instrucção é um meio de governo, e que apoderando-se dele o poder publico, fácil lhe será imprimir idéias falsas ou verdadeiras, salutares ou perniciosas conforme forem as tendências dos que especulam com a prosperidade e a sorte das nações. (A INSTRUCÇÃO PUBLICA, 1873, p. 18).

No periódico, a instrução é vista como redentora de todos os males. Para além de instituição essencial para o progresso, é indispensável para as nações modernas. Pensamento que corrobora o discurso em vigência da época, como destaca Schelbauer (1997, p. 11): “[...] os homens do período vêem na educação a solução para os problemas que as transformações em curso traziam ou ameaçavam trazer." A escola seria o espaço onde a ciência, a moral e o sentimento nacional deveriam ser transmitidos para a sociedade.

Dêem-nos a escola intelligentemente organisada e diligentemente exercida que ella nos fornecerá elementos para dissipar as trevas nos espíritos, para mostrar o caminho das artes e sciencias, para vencer os prejuizos para lutar contra as paixões cegas, para robuster os laços da familia, e o respeito filial, para tornar amável a religião e a moral, para restaurar o imperio da virtude, para semear noções de direito e de justiça, e finalmente para fortalecer o sentimento nacional. (A INSTRUCÇÃO PUBLICA, 1872b, p. 10).

A convicção da capacidade da escola em orientar os homens foi amplamente difundida no século XIX. Na segunda metade do século supracitado, a escola primária era vista como uma necessidade para a propulsão do país. Era fundamental instruir os cidadãos brasileiros, uma vez que era preciso modernizar as relações de produção, pois a abolição da escravidão era dada como certa e o trabalho assalariado precisava ser organizado no Brasil. Outro ponto que demandava o ensino popular era a necessidade de formar o cidadão eleitor, 
pois parte da sociedade civil desejava, do mesmo modo, modernizar a organização política do país. (MACHADO, 2002).

Alambary Luz criticou a forma como as instituições educativas estavam organizadas no Brasil. Ao afirmar que a instrução era propulsora da modernização de um país, desaprovava as instituições brasileiras por não promoverem tal feito, uma vez que as escolas não se preocupavam nem com os aspectos relacionados à higienização, quanto mais pela formação filosófica. Logo, como poderia “[...] esta instrucção, restricta como se acha, de que modo se administra às pobres crianças que muitas delas um dia virão a ser homens eminentes na política, ou nas artes e sciencias?" (A INSTRUCÇÃO PUBLICA, 1872b, p. 10).

Dadas às condições nas quais se encontrava organizado o ensino primário no Brasil, com pouca oferta e organização precária, Alambary Luz declarou a necessidade de seguir os países que estavam na vanguarda do progresso como Alemanha, Suécia, Inglaterra, Estados Unidos e França. Ofertar apenas os rudimentos básicos de escrita, leitura, aritmética e doutrina cristã não era suficiente para se alcançar "[...] intervenção activa, zelosa e consciente que delles espera a constituição brasileira." (A INSTRUCÇÃO PUBLICA, 1872b, p. 10).

Ao retomar alguns anos da publicação do periódico, mais precisamente o ano de 1852, Gonçalves Dias lamentou-se sobre o estado em que se encontrava organizada a instrução pública nas províncias do Norte: "[...] são tão tristes e tão desgraçados os fatos, que a sua exposição singela parece converter a verdade em sátira." (DIAS, 1852, apud ALMEIDA, 1989, p. 337) ${ }^{7}$. Para ele, a instrução popular era alavanca social e não se dava a devida atenção à educação do povo.

Já em relatório de 1872, o ministro do império, Paulino de Souza, ao tratar da organização do ensino primário nas províncias brasileiras, salientou a baixa frequência dos alunos e a ausência de dedicação dos pais em oferecer instrução aos seus filhos. Para o ministro, havia poucos estabelecimentos de ensino, os alunos frequentavam pouco, os pais não se empenhavam em ofertar educação intelectual aos seus filhos e os professores não tinham vocação e zelo para o magistério. (CALVI, 2003). De acordo com os escritos do periódico A Instrucção Publica, a educação pública deveria oferecer conhecimentos suficientes para que as crianças se tornassem homens de sociedade, pais laboriosos e cidadãos patrióticos. Para além da formação desde a tenra idade, o periódico demonstrou preocupação de estender a oferta de escolas a todos os indivíduos. Alambary Luz considerava que a instrução popular era uma necessidade social e lhe creditava o papel de modernizadora do Brasil. Era emergente investir na instrução pública e era necessário que se iniciassem reformas desde a base da educação, destacando-se o ensino primário como primeira preocupação dessas medidas. $\mathrm{O}$ ensino elementar deveria “[...] ser o complexo de elementos que preparem no menino o homem do futuro conscio de suas obrigações e conhecedor de seus direitos.” (A INSTRUCÇÃO PUBLICA, 1873, p. 18). 
Nessa mesma perspectiva, discutiu a necessidade de oferecer, na escola, estudos que apresentassem utilidade prática. De nada adiantaria conhecer as regras gramaticais, trechos dos melhores clássicos, as quatros operações aritméticas e aprender todas as orações do catecismo, se a escola não promovia as aptidões dos indivíduos. Na edição de n. 6 de 1872, no texto A extensão do ensino primário, Alambary Luz questiona

[...] que idéas leva para os usos da vida o menino que assim foi declarado promto? qual é a vocação que se terá revelado acenando às aptidões que possuir? de que modo ganhará o pão quotidiano, quem desconhece todos os caminhos por onde póde seguir a atividade humana? quem ignora a existencia das sciencias e das artes, do commercio e da industria? Quem nunca ouvio falar de direitos e deveres para com seu creador, para com seus semelhantes e para com a pátria? Quem deste modo se vae tornar o instrumento da anarchia ou do despotismo contra a ordem ou a liberdade? Se não for nas escolas primarias, as únicas ao alcance de todos, onde irão colher as verdades sociaes? (A INSTRUCÇÃO PUBLICA, 1872e, p. 41-42).

A preocupação de que a criança deveria se apropriar de conhecimentos úteis à vida adulta, desde pequena, foi uma constante no periódico. A instrução primária era considerada o primeiro contato de ensino institucionalizado e deveria oferecer aos alunos os conhecimentos elaborados. Na edição n. 3 de 1873, Alambary Luz tratou novamente do assunto.

\begin{abstract}
Depois de bem materializado na leitura de livros sem o menor attractivo, nos exercicios de uma arithmetica sem aplicação, na escripta de que se não sabe utilizar, e em centenas de subtilezas grammaticaes, vae o filho do pobre ganhar a vida por qualquer modo estranho a tudo quanto aprendeu na escola, e ignorado tudo quanto o circumda. (A INSTRUCÇÃO PUBLICA, 1873, p. 17-18).
\end{abstract}

Ao tratar da organização do ensino, o periódico criticou o ensino mecânico das escolas, destacando a limitação dos conteúdos, a ineficiência do método e a prática da memorização. Ribeiro de Almeida, colaborador do periódico, destacou que

\begin{abstract}
A instrucção em nossa escola é incompleta; limita-se ao ensino mecanico dos conhecimentos mais elementares, e nenhuma influencia exerce sobre as faculdades intellectuaes e moraes da infância. A leitura reduz-se ao trabalho de juntar syllabas, sem que procure despertar a inteligência do menino, fazendo-o compreender o que lê: e passa-se logo ao ensino da grammatica, que consiste em recitar de cór a lição marcada na vespera. O professor em vez de desenvolver todas as faculdades do espirito por um exercício simultaneo, dirige-se apenas a uma delas, á memoria. (A INSTRUCÇÃO PUBLICA, 1872c, p. 26).
\end{abstract}

O ensino primário apareceu, desde a primeira publicação do periódico, como tema sobre o qual este daria o maior enfoque. Considerado um direito de todos os indivíduos e uma obrigação do Estado, o ensino primário seria uma constante no periódico, fosse em textos assinados pelos editores e professores convidados, nas legislações transcritas e/ou comentadas, nos métodos de ensino ou nas traduções de autores considerados importantes. Os editoriais que trataram do ensino primário apareceram em 41 números e concentraram- 
se, em sua maioria, nos primeiros anos de publicação do periódico. Dentre os temas tratados no periódico acerca do ensino primário, sobressai-se o número de publicações sobre a formação dos professores e os métodos de ensino.

Alambary Luz atribuiria ao ensino primário o papel principal na formação popular, afirmando que "A instrucção primaria é para os povos o que é o alicerce para um edifício." (A INSTRUCÇÃO PUBLICA, 1873, p. 17), ou seja, sem o ensino primário, de nada adiantaria aos governos investir nas demais etapas de ensino. Ao tratar dos problemas da instrução pública, Alambary Luz apresenta o quanto o ensino primário não se apresentava estruturado enquanto instituição responsável por formar os cidadãos.

\begin{abstract}
Escola sem apropriada mobília, organisação pedagogica defeituosa, estudos elementares materializados, professores que se formam a si proprios, ausencia de methodo para o ensino, falta absoluta de um programma e de livros para desenvolver a intelligencia dos alumnos, por toda a parte desgosto, impaciencia, desanimo e tedio... eis o que se encontra na quasi totalidade de nossas casas de educação publica! (A INSTRUCÇÃO PUBLICA, 1872a, p. 2).
\end{abstract}

Outros temas foram tratados no periódico com relevância, como a liberdade de ensino e a obrigatoriedade de frequência; a educação física e a disciplina de ginástica; a coeducação e o ensino para as mulheres, entre outros. $\mathrm{O}$ enfoque maior foi para a formação dos professores e os métodos de ensino para uso dos docentes nas escolas primárias. Preocupação que se justificava pela escassez no período de formação institucionalizada para os docentes, uma vez que poucos professores primários possuíam curso normal, seja pela ausência de escolas normais ou pela legislação em vigência que permitia a formação pela prática de professor adjunto.

Em alguns momentos o periódico associaria a ineficiência do ensino primário à ausência ou pouca formação dos professores. No texto $\mathbf{O}$ ensino primário, publicado na edição de n. 5 de 1872, Alambary Luz defendeu que os "[...] mestres escolas são em nossas sociedades modernas [...] artifices obscuros a quem está confiada a maior obra da civilização do gênero humano" (A INSTRUCÇÃO PUBLICA, 1872d, p. 33), mas que, no caso da instrução brasileira, não exerciam a função a eles confiada.

Alambary Luz argumentou que ao professor não bastava o desejo de ser útil, mas que era necessário, além dos conhecimentos rudimentares de linguagem, cálculo e escrita, o título de exercício de docência. Ao questionar a ausência da exigência de conhecimentos sobre a pedagogia para o ingresso na carreira docente, contestou o papel conivente da administração pública a essa situação.

Alambary Luz considerava o ensino primário essencial para a formação do cidadão e importantíssimo na constituição do indivíduo, enquanto fiscalizadores dos atos do governo, como forma de garantir os direitos e a liberdade daquele. Para que houvesse o equilíbrio entre governo e cidadãos, para que o pacto existisse de maneira harmoniosa, defendeu que 
os indivíduos precisavam ter a consciência das funções que deveriam exercer na sociedade. Essa consciência só seria adquirida com acesso à instrução, no caso das classes populares, à instrução primária pública.

\section{CONSIDERAÇÕES FINAIS}

O objetivo desse texto foi investigar o periódico especializado em educação $\mathbf{A}$ Instrucção Publica. Criado com o intuito de discutir sobre os problemas da instrução pública preocupou-se em divulgar modelos educacionais para a organização da escola brasileira. Alambary Luz, enquanto diretor e principal autor dos textos do periódico, defendia que a modernização do país só se alcançaria após a organização da instrução pública, que deveria ser de qualidade e ofertada a todos.

A imprensa especializada em educação permite a apreensão das diversas propostas educacionais veiculadas para a organização da instrução. Ao defender, criticar e/ou propor modelos de ensino, os periódicos divulgam a voz de determinado grupo dentro da sociedade. No caso do periódico A Instrucção Publica, representava um grupo de intelectuais que se opunham ao ensino tradicional em vigência nas escolas, defendendo a modernização da instrução pública e das práticas pedagógicas.

Compreender o debate sobre a institucionalização e oferta da instrução primária, realizado na segunda metade do século XIX por meio da imprensa, especialmente os periódicos especializados em educação, permite apreender as propostas educacionais que circulavam entre os intelectuais do período. Ao confrontar com outras fontes é possível observar o embate entre os diversos interesses existentes e a pluralidade de vozes que se manifestavam na imprensa.

Diante disso, o periódico se propunha a oferecer meios para o aprimoramento da atuação docente, e consequentemente, na melhora da instrução pública. Ao discutir sobre a organização da escola primária pública, divulgava um modelo educacional que entendia a escola como espaço para aprimoramento da sociedade e do desenvolvimento econômico e cultural do país. Seria a escola responsável por resolver todos os males e problemas do Brasil. Ofertada às classes populares, incumbir-se-ia de preparar os homens para a modernização da sociedade brasileira.

\section{REFERÊNCIAS}

A INSTRUCÇÃO PUBLICA. Rio de Janeiro: Typographia Cinco de Março, n. 1, 1872a.

A INSTRUCÇÃO PUBLICA. Rio de Janeiro: Typographia Cinco de Março, n. 2, 1872b.

A INSTRUCÇÃO PUBLICA. Rio de Janeiro: Typographia Cinco de Março, n. 4, 1872c. 
A INSTRUCÇÃO PUBLICA. Rio de Janeiro: Typographia Cinco de Março, n. 5, 1872d.

A INSTRUCÇÃO PUBLICA. Rio de Janeiro: Typographia Cinco de Março, n. 6, 1872e.

A INSTRUCÇÃO PUBLICA. Rio de Janeiro: Typographia Cinco de Março, n. 19, 1872f.

A INSTRUCÇÃO PUBLICA. Rio de Janeiro: Typographia Cinco de Março, n. 27, 1872g.

A INSTRUCÇÃO PUBLICA. Rio de Janeiro: Typographia Cinco de Março, n. 28, 1872h.

A INSTRUCÇÃO PUBLICA. Rio de Janeiro: Typographia Cinco de Março, n. 3, 1873.

A INSTRUCÇÃO PUBLICA. Rio de Janeiro: Typographia Cinco de Março, n. 52, 1874.

ALMEIDA, J. R. P. de. História da Instrução Pública no Brasil (1500-1889): história e legislação. Trad. Antonio Chizzotti. São Paulo, SP: EDUC; Brasília, DF: INEP/MEC, 1989.

BASTOS, M. H. C. Apêndice - A imprensa periódica educacional no Brasil: de 1808 a 1944. In: CATANI, D. B.; BASTOS, M. H. C. (Org.). Educação em revista: a imprensa periódica e a história da educação. São Paulo: Escrituras, 2002. p. 173-187.

BRASIL. Diretoria Geral de Estatística. Relatório dos trabalhos estatísticos apresentados $\mathrm{Ilm}^{\circ} \mathrm{Exm}^{\circ}$ Sr. Conselheiro Dr. José Bento da Cunha Figueiredo, Ministro e Secretário de Estado dos Negócios do Império pelo Diretor Geral conselheiro Manoel Francisco Correia, em 31 de dezembro de 1876. Rio de Janeiro, Tipografia de Hipólito José Pinto, 1877.

CALVI, L. M. As transformações sociais e a instrução pública: uma análise dos projetos reforma educacional e dos relatórios ministeriais de 1868 a 1879 no Brasil. 2003. $160 \mathrm{f}$. Dissertação (Mestrado em Educação) - Programa de Pós-graduação em Educação, Universidade Estadual de Maringá, Maringá, 2003.

DIÁRIO DO RIO DE JANEIRO. Rio de Janeiro: Typografia do Diario do Rio de Janeiro, n. 102, 1872.

GONDRA, J. G.; SCHUELER, A. F. M. Educação, poder e sociedade no império brasileiro. São Paulo, SP: Cortez, 2008.

INSTITUTO BRASILEIRO DE GEOGRAFIA E ESTATÍSTICA - IBGE. Repertório Estatístico do Brasil: quadros retrospectivos. Rio de Janeiro: IBGE, 1986.

KUHLMANN JUNIOR, M. A educação infantil no século XIX. In: STEPHANOU, M.; BASTOS, M. H. C. (Org.). Histórias e memórias da educação no Brasil: século XIX. 2. ed. Petrópolis, RJ: Vozes, 2006. p. 68-77. v. 2.

MACHADO, M. C. G. O decreto de Leôncio de Carvalho e os pareceres de Rui Barbosa em debate: a criação da escola para o povo no Brasil no século XIX. In: STEPHANOU, 
M.; BASTOS, M. H. C. (Org.). Histórias e memórias da educação no Brasil: século XIX. 2. ed. Petrópolis, RJ: Vozes, 2006. p. 91-115. v. 2.

MACHADO, M. C. G. O papel educativo da imprensa na formação do cidadão republicano brasileiro: a atuação de Rui Barbosa e José Veríssimo. História \& Perspectivas, Uberlândia, n. 38, p. 213-235, 2008.

MACHADO, M. C. G. Rui Barbosa: pensamento e ação. Campinas, SP: Autores Associados; Rio de Janeiro, RJ: Fundação Casa Rui Barbosa, 2002.

MACHADO, M. C. G.; CARVALHO, C. H. Intelectuais, educação e imprensa: perspectivas teórico-metodológicas à História da Educação. In: CONGRESSO LUSOBRASILEIRO DE HISTÓRIA DA EDUCAÇÃO, 11., 2016, Porto. Anais ... Porto: COLUBHE; Faculdade de Letras da Universidade do Porto, 2016. p. 743-755.

MACHADO, M. C. G.; RODRIGUES, E. Conversas sobre fontes. In: GONDRA, J. G.; MACHADO, M. C. G.; SIMÕES, R. H. S. (Org.). História da educação, matrizes interpretativas e internalização. Vitória, ES: EDUFES, 2017. p. 253-271.

REVISTA PEDAGÓGICA. Rio de Janeiro: Classica de Alves \& C., 1892. n. 18.

SCHELBAUER, A. R. Idéias que não se realizam: o debate sobre a educação do povo no Brasil de 1870 a 1914. Maringá, PR: EDUEM, 1997.

SCHUELER, A. F. M. de. Representações da docência na imprensa pedagógica na Corte imperial (1870-1889): o exemplo da Instrução Pública. Educação e Pesquisa, São Paulo, v. 1, n. 3, p. 379-390, set./dez. 2005.

VILLELA, H. O. S. Da palmatória a lanterna mágica: a Escola Normal da Província do Rio de Janeiro entre o artesanato e a formação profissional (1868-1876). 2002. 343 f. Tese (Doutorado em Educação) - Faculdade de Educação, Universidade Estadual de São Paulo, São Paulo, 2002.

VILLELA, H. O. S. O mestre-escola e a professora. In: LOPES, E. M. T.; FARIA FILHO, L. M.; VEIGA, C. G. (Org.). 500 anos de Educação no Brasil. 3. ed. 1. reimp. Belo Horizonte, MG: Autentica, 2007. p. 95-134.

\section{Notas}

${ }^{1}$ É doutoranda em educação, pelo Programa de Pós-graduação em Educação (PPE), da Universidade Estadual de Maringá (UEM). É Mestre em Educação pela UEM.

${ }^{2}$ É Doutora em educação pela Universidade Estadual de Campinas (UNICAMP). Professora titular do Departamento de Fundamentos da Educação e do Programa de Pós-graduação em Educação da Universidade Estadual de Maringá (UEM). Bolsista Produtividade 1C do CNPq com pós-doutorado em Educação pela Universidade Federal de Minas Gerais (UFMG). 


\section{Revista HIISTEIDBR On-line}

${ }^{3}$ É Doutor em educação pela Universidade Estadual de Maringá (UEM). Professor da Universidade Federal do Tocantins, com pós-doutorado em Educação pela Universidade Federal de Uberlândia (UFU).

${ }^{4}$ Optou-se por transcrever as citações mantendo-se a grafia original.

${ }^{5}$ Contemporâneo do período em que o periódico foi publicado José Ricardo Pires de Almeida publicou o livro História da Instrução Publica no Brasil (1500-1889), em francês, no ano de 1889. Somente no ano de 1989 sua obra foi traduzida e publicada em português.

6 Sobre o decreto de Leôncio de Carvalho, consultar o texto Notas para a História da educação: considerações acerca do decreto $\mathrm{n}^{0} \mathbf{7 . 2 4 7}$, de 19 de abril de 1879, de autoria de Carlos Leôncio de Carvalho, Cristiane Silva Melo e Maria Cristina Gomes Machado.

${ }^{7} \mathrm{O}$ relatório de Antônio Gonçalves Dias, utilizado nessa pesquisa, foi publicado na íntegra no livro História da Instrução Publica no Brasil (1500-1889), de José Ricardo Pires de Almeida.

Submetido em: 09/04/2018

Aprovado em: 30/05/2018

Publicado em: 22/06/2018 